\title{
Prevalence of, and Risk Factors for, Physical Disability among Nurses in Europe
}

\author{
Beatrice Van der Heijden $1,2,3,4,5^{*}$, Madeleine Estryn-Béhar6, Hans Heerkens ${ }^{7}$ \\ ${ }^{1}$ Institute for Management Research, Radboud University, Nijmegen, The Netherlands \\ ${ }^{2}$ Open University of the Netherlands, Heerlen, The Netherlands \\ ${ }^{3}$ Ghent University, Ghent, Belgium \\ ${ }^{4}$ Hubei University, Wuhan, China \\ ${ }^{5}$ Kingston University, London, UK \\ ${ }^{6}$ Retired from Service Central de Médecine du Travail Hôpitaux Hôtel Dieu AP-HP de Paris, Paris, France \\ ${ }^{7}$ Department Industrial Engineering \& Business Information Systems, Faculty of Behavioural, Management \& Social Sciences, \\ University of Twente, Enschede, The Netherlands \\ Email: *b.vanderheijden@fm.ru.nl
}

How to cite this paper: Van der Heijden B., Estryn-Béhar, M. and Heerkens, H. (2019) Prevalence of, and Risk Factors for, Physical Disability among Nurses in Europe. Open Journal of Social Sciences, 7, 147-173.

https://doi.org/10.4236/jss.2019.711012

Received: September 16, 2019

Accepted: November 17, 2019

Published: November 20, 2019

Copyright $\odot 2019$ by author(s) and Scientific Research Publishing Inc. This work is licensed under the Creative Commons Attribution-NonCommercial International License (CC BY-NC 4.0). http://creativecommons.org/licenses/by-nc/4.0/

\begin{abstract}
Aims and objectives: This study investigates possible causes of physical disability among European nurses, and deals with personal, physical and (social) work environment factors. Design: 39,898 (51.7\%) nurses responded to our survey (6335 head nurses; 4933 specialized nurses; 24,142 state-registered nurses; and 4488 nursing aids). Methodology: First, the prevalence of physical disability among nurses in Europe was investigated. Second, multivariate analyses were performed to better understand the influence of possible risk factors for physical disability. A Strobe statement has been added. Results: In general, the risk of physical disability is positively associated with the amount of physical load and the nurses' dissatisfaction with this, with a lack of teamwork quality, harassment by supervisors, colleagues not (quite) ready to help, not having lifting aids, a high quantitative work demand, and having to work in split shifts. The main moderating or buffering factors addressed in this study are having a part-time job, practice of sport and/or hobbies, and the nurses' social work environment. Relevance to Clinical Practice: Today, there is a substantial shortage of nurses in Europe, and management in healthcare organizations that fails to improve physical working conditions and to provide adequate (career) support might suffer from, will experience growing levels of disability and dissatisfaction among nursing staff that might result in premature leave, reduced productivity or higher absenteeism.
\end{abstract}

\section{Keywords}

Nurses, Physical Disability, Personal Factors, Physical Work Environment, 
Social Work Environment, Premature Leave

\section{Introduction}

Today, there is a substantial shortage of nurses in Europe. Demographic changes in the coming years might worsen this situation if no action is taken (cf. [1]). The study that is reported in this contribution forms part of the European NEXT study ${ }^{1}$ which is aimed at enlarging our understanding of so-called sustainable work ability [2] or employability (career potential) [3] [4] [5] until a reasonable age of retirement. Obviously, nurses' physical ability to work is one of the key factors in order to enable them to stay active at the labour market, and to help prevent premature leave [1].

Previous research has already indicated that physical disability is a common problem among nurses [6] [7] [8], comprising a professional category of employees who have to perform their tasks in an environment that is characterized by both high physical (e.g. lifting and bending) and psychosocial risk factors (e.g. stress at work) [9] that contribute to physical disability [8] [10]. However, while the nursing profession is represented in different parts of the health care system, studies often do not differentiate between different qualification or occupational levels of nurses nor among types of institutions where nurses work [11]. Moreover, research sampling nurses working in nursing homes and home care is rare (cf. [10] [12]).

This study adds to our understanding of the prevalence of, and risk factors for, physical disability among nurses by taking into account both personal, physical and social working environment factors. Moreover, a large sample incorporating nurses from ten European countries working at a variety of occupational levels (head nurses, specialized nurses, state-registered nurses, and nursing aids) across hospitals, nursing homes, and home care institutions has been used for this empirical work. To the best of our knowledge, this is the first study to take such a wide perspective, herewith adding to our knowledge on the generalizability of research on physical disability. As nurses' working conditions may vary considerably across countries and institutional settings, the objective of our broad sampling strategy is to add to the ecological validity of research on physical disability.

In the next section, we will go into the theoretical background of the concept of physical disability, and some of its possible determinants.

\section{Theoretical Background; Physical Disability and Its Determinants}

Nursing requires tasks and duties to be carried out, without time delay, and, in many cases, under highly stressful circumstances [13] [14]. It often involves ${ }^{1}$ The NEXT study was financed by the European Commission within the Fifth Framework, Project ID: QLK-6-CT-2001-00475. 
working in awkward positions, prolonged standing, and lifting heavy loads. These aspects can be characterized as physical load. Nursing is among the high-risk occupations with respect to low back problems; a major indicator for physical disability [15], with a point prevalence of approximately $17 \%$, an annual (period) prevalence of $40 \%$ to $50 \%$, and a life-time prevalence of $35 \%$ to $80 \%$ [7]. Hignett (1996), who performed a meta-analysis of over 80 studies, concluded that more frequent patient handling correlates significantly with increased incidence of low back pain, and called for more research to determine additional contributing factors [7] (cf. [16] [17]).

Physical load has long been acknowledged as one of the major contributors to the high incidence of physical disability among nurses. In particular, the combination of mechanical and psychosocial stress at work has been identified to be an important determinant for the onset of low back pain, and neck or upper-extremity musculoskeletal complaints, resulting in an increase in health-related absenteeism [7] [18] [19] [20] [21] [22], and not infrequently, even premature departure from the nursing profession [1] [23], resulting in the loss of desperately needed health care workers.

Occupational health scholars describe nursing as a profession with a high prevalence of back-related complaints [8]. In Germany, for example, data from a major health insurance company indicated that $56 \%$ of all reported sick days of nurses in in-patient units are due to Musculoskeletal Diseases (MSDs), and that MSDs constitute the most reported cause for sick leave [24]. Similar rates have been reported from research in the USA [25], the UK [26], and the Netherlands [27] (see also [28]).

Fuortes, Shi, Zhang, Zwerling, and Schootman (1994) showed that performing combined lifting activities is a significant risk factor for back injury [29]. In a similar vein, Smedley et al. (2003) emphasized the impact of specific nursing activities, such as bedding or lifting patients [26]. Estryn-Behar et al. (1990) and Lagerström, Wenemark, Hagberg, and Hjelm (1996) added the importance of uncomfortable posture, and standing more than six hours a day [21] [30], in their theoretical framework aimed to understand the prevalence of physical disability, its determinants, and its consequences. Lagerström and associates (1996) stressed the added value of including psychosocial factors, such as one's social working environment [30] (see also [31] [32]) in their research on physical disability.

Despite the heterogeneous composition of the nursing profession, in their review on MSDs, Sherehiy et al. (2004) only identified a few studies differentiating between categories of nurses, and called for more analyses according to occupational level and health care setting [11]. Moreover, although back pain and, to a lower extent, disability due to back pain among nurses working in hospitals has been extensively investigated, research focussing on nurses working in nursing homes and home care is rare (cf. [10] [12]).

The study that is reported in this contribution aims to build upon previous scholarly work in this field of knowledge by comprising an explicit representa- 
tion of the heterogeneous composition of the nursing profession. More specially, we investigated possible determinants of physical disability, taking into account both personal, physical and social working environment factors (see [1] for more details), across ten European countries (Belgium, Germany, Great Britain, Finland, France, Italy, the Netherlands, Norway, Poland, and Slovakia), and compared four categories of occupational levels (head nurses, specialized nurses, state-registered nurses, and nursing aids) working in three types of health care institutions (hospitals, nursing homes, and home care institutions).

\section{Methodology}

\subsection{Procedure and Sample}

This study forms part of the European NEXT study that was aimed to identify why nurses are leaving their profession early, often earlier than members of other professions. The multi-disciplinary NEXT study team (consisting of professionals working across the areas of medical science, psychology, and nursing) has recruited a numerous amount of health care institutions for participation in a survey, taking into account applicable ethical guidelines (see [1] for all specific information); The Next Study design has been approved by the Ethical Committee of a German University), and adherence to STROBE has been taken into account (see Supplementary file 1). The survey was sent to 77,681 nurses, of whom 39,898 (51.7\%) responded. Different procedures for distribution of the anonymous questionnaires were used. Direct posting from the NEXT teams to the participants' home address was preferred. This was possible in some countries after agreement of all parties involved. In some instances the institutions put on the address label themselves to avoid handing out addresses. In other cases the questionnaires were sent to participants via the institution's internal mail. In order to conduct our analyses, we grouped the nurses according to their occupational level. The first group, the head nurses, comprised 6335 nurses that were working in a supervisory position. The category of specialized nurses comprised 4933 nurses. The third group, the state-registered nurses, comprised 24,142 nurses, and the fourth group consisting of nursing aids, with lower nursing education, comprised 4488 nurses. In order to enhance generalization, respondents were sampled across three different kinds of health care institutions, taking into account the specific geographical distribution in each country: hospitals $(N=$ $147)$, nursing homes $(N=185)$, and home care institutions $(N=76)$. Of all participating nurses, $76.7 \%$ worked in hospitals, $10.0 \%$ in nursing homes, and 13.3 in home care institutions.

\subsection{Measures}

For all scales used in the study and described below satisfactory psychometric properties have been found [33]. The translation-back translation methodology was used for each participating country [34], i.e. the measurement scales were translated from one language to another and then back-translated to the original language by an independent translator. The purpose of this double translation 
was to allow experts to examine both versions of each questionnaire item to establish conformity of meaning. Where inconsistencies were found, the items were reformulated or, if necessary eliminated. Subsequently, all scales were carefully pilot-tested in up to six tests in three countries. Next to testing the psychometric properties of the measurement scales, linguistic testing for comprehensibility was also performed.

\subsubsection{Physical Disability}

Physical disability was measured using two indicators, i.e. Von Korff et al.'s (1992) disability measure [35], and quantity of musculoskeletal disorders. This measure assesses the nurses' physical health and consists of a four-item instrument to measure peoples' disability due to low back pain and neck/shoulder complaints. An example item was: "Considering the past half year, how much has neck or low back pain interfered with your daily activities?". The response categories ranged from 0 (no interference or change) to 10 (highest interference or very much change). The internal consistency reliability estimate, using Cronbach's alpha, varied between 0.72 and 0.77 , depending upon country. Back- or neck-pain-related disability was considered to be low for nurses scoring 0 , to be medium for nurses scoring from 1 through 2 , and to be high for nurses scoring from 3 through 10 .

The second factor that was used to operationalize physical disability, MSD, was measured by means of one item [the respondents were asked to mark a list of current diseases or injuries: "Musculoskeletal disease in back, limbs or other part of the body (e.g. repeated pain in joint or muscle, sciatica, rheumatism, arthritis)"] [2].

\subsubsection{Antecedents of Physical Disability}

The personal factors that were included in our study comprised age, gender, occupational level, seniority (<5 years of experience; 5 - 14 years; 15 - 24 years; and $\geq 25$ years), number of children, time spent on sports and/or hobbies (each week or several times per month; seldom or never), and having to work in split shifts or not (two work periods in the same day). Working week duration was operationalized as "average number of working hours per week according to work contract". This variable was dichotomized into: a) "less than 35 hours per week" and b) " $\geq 35$ hours per week".

The category of physical working conditions comprised two factors, i.e. physical load, and satisfaction with the physical working conditions. Physical load was measured using three items that were constructed by the NEXT study group [1] (physical load major factors in nursing index): a) "lifting patients in bed without aid", b) "maintaining an uncomfortable posture", and c) "working in a standing posture". The response categories for the first two items were: 1 ) " 0 to 1 times a day", 2) " 2 to 5 times a day", 3) "6 to 10 times a day" 4) "more than 10 times a day". The response categories for the third item were: 1) less than 2 hours, 2) 2 to 3 hours, 3) 4 to 5 hours, and 4) 6 hours or more. The final score has been computed as a sum score divided by three. The internal consistency re- 
liability estimate, using Cronbach's alpha, varied between 0.60 and 0.77 , depending upon country. Physical load was considered to be low when scored from 1 through 2, medium when scored from 2.1 through 2.99, and high when scored from 3 through 4.

The second factor, i.e. Satisfaction with the physical working conditions, was measured using one item of the Kristensen's (2000) four-item scale for job satisfaction: "How pleased are you with your physical working conditions?" [36]. Responses were made on a four-point rating scale ( $1=$ very unsatisfied, and $4=$ highly satisfied).

(Social) working environment was measured by means of four aspects; quality of teamwork, harassment by superior, readiness of colleagues to help, and quantitative demand.

Quality of teamwork was operationalized by means of some items from the Copenhagen Psychosocial Questionnaire [37] and some items created by the NEXT Study group. Quality of teamwork comprised four items dealing with satisfaction with teamwork and four items dealing with quality of information sharing. An example item for satisfaction with teamwork was: "How pleased are you with psychological support at your workplace?" A four-point rating scale was used ranging from "very unsatisfied" to "highly satisfied". The internal consistency reliability estimate, using Cronbach's alpha, varied between 0.68 and 0.76, depending upon country. An example item for Quality of information sharing was: "How often do you receive information, which is relevant to your work, insufficiently or too late?". A five-point rating scale was used for three of the four items: "never", "less than once per week", "about 1 to 5 times per week", "about 1 to 5 times per day" and "constantly". We also included one item which was formulated as follows: "In your department, are there opportunities to discuss professional matters which you think are important?" with the following response categories: "no", "yes, briefly" and "yes, in detail". The internal consistency reliability estimate, including all four items, using Cronbach's alpha, varied from 0.76 to 0.82 , depending upon country. Scores ranging from 3.6 through 5 were considered as low, from 2.6 through 3.59 as medium, and from 1 through 2.59 as high.

Harassment by superiors was measured with one item: "At your work place, are you subjected to harassment by your superiors?" A five-point rating scale has been used, ranging from: "never" to "daily". This variable was dichotomized with a split between "very seldom" and "monthly".

Readiness of colleagues to help was measured by means of one item: "In general, are your near colleagues ready to help you with the performance of your task?". A five-point rating scale has been used, ranging from: "they show little readiness to help" to "they are very willing to help me". The variable was dichotomized adding a split between 3 (low/medium) and 4 (high).

Quantitative demand was measured using a four-item scale [37]. Quantitative work demand refers to demands in terms of number of work hours (extensive demand) and/or work pace (intensive demand). An example item was: "How 
often do you lack time to complete all your work tasks?". The internal consistency reliability estimate, using Cronbach's alpha, varied between 0.62 and 0.72 , depending upon country. Scores ranging from 1 through 2.4 were considered as low, from 2.5 through 3.5 as medium, and from 3.6 through 5 as high.

\subsection{Analyses and Preliminary Results}

First, we have studied the prevalence of back- and neck-pain-related disability, MSDs, and dissatisfaction with physical working conditions across countries and occupational settings by comparing all the corresponding percentages (see Table 1); Only some parts of the NEXT study survey were used in a Norwegian research project, therefore we do not have complete variable information for Norway; Dissatisfaction with physical working conditions has been incorporated in this table given the fact that Norwegian data were available for this variable as well, while for Table 2 variables Norwegian data were not available, herewith saving manuscript space). Next, the prevalence of physical working conditions has been dealt with (see Table 2). First the outcomes for physical load average of the sum score comprising the three items, see the Methodology section, are given, followed by more specific details regarding "maintaining an uncomfortable posture" and "working in a standing posture" (see Table 2).

Second, we conducted multivariate analyses (specifically, backwards stepwise binary logistic regressions with 95\% confidence intervals) using SPSS 12.0. All personal factors that were found to be significantly linked with back- or neck-pain-related disability (high) and MSDs (high) in bivariate analyses were included in the regressions and removed step by step when not significant.

\section{Results}

\subsection{Frequency of Back- and Neck-Pain-Related Disability and of Musculoskeletal Disorders}

The greatest proportion of high scores for the "Von Korff et al.'s (1992) disability measure" was found among nursing aids (26.1\%), followed by the state-registered nurses $(21.7 \%)$, the head nurses (19.6\%), and the specialized nurses (13.9\%) (see Table 1 for more specific outcomes). The highest proportion of MSDs was found among nursing aids and state-registered nurses (for nursing aids: $24.0 \%$ following one's own diagnosis, and 30.9\% following a physician's diagnosis; and for state-registered nurses: $25.2 \%$ following one's own diagnosis, and $28.5 \%$ following a physician's diagnosis). Head nurses declared slightly more MSDs $(23.0 \%$ following one's own diagnosis, and 30.9\% following a physician's diagnosis) compared with specialized nurses (19.7\% own diagnosis, and $26.3 \%$ physician's diagnosis).

\subsection{Frequency of Dissatisfaction about Physical Working Condition and Amount of Physical Load}

The greatest proportion of nurses that reported to be "unsatisfied about their physical working conditions" was found among state-registered nurses $(9.7 \%$ 
Table 1. Prevalence of physical disability of nurses, and dissatisfaction with physical working conditions according to occupational level and country.

\begin{tabular}{|c|c|c|c|c|c|c|c|c|c|c|c|c|}
\hline \multicolumn{2}{|c|}{ Occupational level } & NL & $\mathrm{BE}$ & $\mathrm{DE}$ & FIN & FR & GB & IT & $\mathrm{N}$ & POL & SLK & Total \\
\hline \multicolumn{13}{|c|}{ Back- and neck-pain-related disability score $(N=30,144)$} \\
\hline \multirow{4}{*}{ Head nurses } & Low & & $65.1 \%$ & $51.0 \%$ & $67.0 \%$ & $62.2 \%$ & $75.2 \%$ & $58.4 \%$ & & $46.6 \%$ & $35.0 \%$ & $58.8 \%$ \\
\hline & Medium & & $22.7 \%$ & $22.1 \%$ & $19.0 \%$ & $22.1 \%$ & $14.3 \%$ & $19.2 \%$ & & $28.7 \%$ & $31.8 \%$ & $21.6 \%$ \\
\hline & High & & $12.2 \%$ & $26.9 \%$ & $14.1 \%$ & $15.7 \%$ & $10.6 \%$ & $22.4 \%$ & & $24.7 \%$ & $33.2 \%$ & $19.6 \%$ \\
\hline & Number & & 370 & 614 & 306 & 299 & 644 & 438 & & 401 & 277 & 3349 \\
\hline \multirow{4}{*}{ Spec. nurses } & Low & $80.6 \%$ & $67.5 \%$ & $51.9 \%$ & $67.9 \%$ & $63.4 \%$ & $76.4 \%$ & $49.9 \%$ & & & $35.5 \%$ & $67.4 \%$ \\
\hline & Medium & $13.0 \%$ & $19.1 \%$ & $20.5 \%$ & $20.0 \%$ & $19.8 \%$ & $14.6 \%$ & $28.6 \%$ & & & $30.3 \%$ & $18.8 \%$ \\
\hline & High & $6.4 \%$ & $13.4 \%$ & $27.5 \%$ & $12.1 \%$ & $16.8 \%$ & $9.1 \%$ & $21.5 \%$ & & & $34.2 \%$ & $13.9 \%$ \\
\hline & Number & 1009 & 627 & 385 & 1014 & 262 & 563 & 409 & & & 152 & 4421 \\
\hline \multirow{4}{*}{$\begin{array}{l}\text { State- } \\
\text { registered } \\
\text { nurses }\end{array}$} & Low & $78.5 \%$ & $60.3 \%$ & $44.9 \%$ & $64.6 \%$ & $58.6 \%$ & $71.5 \%$ & $51.3 \%$ & & $40.9 \%$ & $34.2 \%$ & $53.8 \%$ \\
\hline & Medium & $15.1 \%$ & $23.7 \%$ & $26.0 \%$ & $22.8 \%$ & $21.4 \%$ & $17.7 \%$ & $24.4 \%$ & & $31.8 \%$ & $30.0 \%$ & $24.5 \%$ \\
\hline & High & $6.5 \%$ & $15.9 \%$ & $29.1 \%$ & $12.6 \%$ & $20.0 \%$ & $10.7 \%$ & $24.4 \%$ & & $27.3 \%$ & $35.8 \%$ & $21.7 \%$ \\
\hline & Number & 2376 & 2232 & 1826 & 715 & 2160 & 745 & 3871 & & 3454 & 1736 & 19115 \\
\hline \multirow{4}{*}{ Nursing aids } & Low & $79.3 \%$ & $47.5 \%$ & $38.8 \%$ & $51.0 \%$ & $48.1 \%$ & $71.6 \%$ & & & $47.1 \%$ & $23.6 \%$ & $52.2 \%$ \\
\hline & Medium & $10.7 \%$ & $27.9 \%$ & $23.1 \%$ & $23.4 \%$ & $23.3 \%$ & $15.3 \%$ & & & $29.4 \%$ & $22.6 \%$ & $21.7 \%$ \\
\hline & High & $9.9 \%$ & $24.7 \%$ & $38.1 \%$ & $25.5 \%$ & $28.6 \%$ & $13.1 \%$ & & & $23.5 \%$ & $53.8 \%$ & $26.1 \%$ \\
\hline & Number & 382 & 373 & 281 & 145 & 1680 & 275 & & & 17 & 106 & 3259 \\
\hline$p$ & & $* *$ & $* * *$ & $* * *$ & $* * *$ & $* * *$ & $\mathrm{~ns}$ & $* *$ & & ns & * & $* * *$ \\
\hline \multicolumn{13}{|c|}{ Musculoskeletal disorders (MSD) $(N=35,736)$} \\
\hline \multirow{5}{*}{ Head nurses } & No & & $51.2 \%$ & $36.3 \%$ & $54.3 \%$ & $40.9 \%$ & $58.7 \%$ & $45.5 \%$ & $57.1 \%$ & $36.5 \%$ & $33.0 \%$ & $46.2 \%$ \\
\hline & Yes own diagnosis & & $15.8 \%$ & $24.7 \%$ & $18.9 \%$ & $32.6 \%$ & $18.4 \%$ & $21.9 \%$ & $19.8 \%$ & $25.9 \%$ & $34.3 \%$ & $23.0 \%$ \\
\hline & Yes physician Dg. & & $33.0 \%$ & $39.0 \%$ & $26.9 \%$ & $26.5 \%$ & $22.9 \%$ & $32.6 \%$ & $23.1 \%$ & $37.6 \%$ & $32.7 \%$ & $30.9 \%$ \\
\hline & Number & & 406 & 656 & 376 & 328 & 669 & 512 & 268 & 394 & 315 & 3924 \\
\hline & No & $61.5 \%$ & $53.7 \%$ & $41.4 \%$ & $54.3 \%$ & $49.6 \%$ & $63.6 \%$ & $44.1 \%$ & & & $42.0 \%$ & $54.0 \%$ \\
\hline \multirow{3}{*}{ Spec. nurses } & Yes own diagnosis & $14.3 \%$ & $20.7 \%$ & $20.2 \%$ & $22.4 \%$ & $26.4 \%$ & $16.8 \%$ & $17.7 \%$ & & & $32.0 \%$ & $19.7 \%$ \\
\hline & Yes physician Dg. & $24.3 \%$ & $25.7 \%$ & $38.4 \%$ & $23.3 \%$ & $23.9 \%$ & $19.6 \%$ & $38.2 \%$ & & & $26.0 \%$ & $26.3 \%$ \\
\hline & Number & 1038 & 697 & 411 & 1170 & 276 & 583 & 479 & & & 181 & 4835 \\
\hline \multirow{4}{*}{$\begin{array}{l}\text { State- } \\
\text { registered } \\
\text { nurses }\end{array}$} & No & $61.9 \%$ & $49.2 \%$ & $37.4 \%$ & $58.0 \%$ & $45.0 \%$ & $58.3 \%$ & $40.4 \%$ & $58.2 \%$ & $39.8 \%$ & $38.6 \%$ & $46.3 \%$ \\
\hline & Yes own diagnosis & $15.2 \%$ & $18.1 \%$ & $23.2 \%$ & $22.0 \%$ & $30.6 \%$ & $21.4 \%$ & $27.4 \%$ & $20.4 \%$ & $30.4 \%$ & $35.3 \%$ & $25.2 \%$ \\
\hline & Yes physician Dg. & $23.0 \%$ & $32.7 \%$ & $39.4 \%$ & $20.0 \%$ & $24.4 \%$ & $20.2 \%$ & $32.2 \%$ & $21.4 \%$ & $29.8 \%$ & $26.1 \%$ & $28.5 \%$ \\
\hline & Number & 2457 & 2576 & 1942 & 824 & 2338 & 751 & 4573 & 1778 & 3505 & 1971 & 22715 \\
\hline \multirow{4}{*}{ Nursing aids } & No & $59.5 \%$ & $36.9 \%$ & $38.8 \%$ & $56.0 \%$ & $40.6 \%$ & $68.5 \%$ & & $47.7 \%$ & $31.3 \%$ & $34.4 \%$ & $45.1 \%$ \\
\hline & Yes own diagnosis & $16.8 \%$ & $20.7 \%$ & $14.7 \%$ & $17.9 \%$ & $29.8 \%$ & $10.2 \%$ & & $23.2 \%$ & $43.8 \%$ & $34.4 \%$ & $24.0 \%$ \\
\hline & Yes physician Dg. & $23.7 \%$ & $42.4 \%$ & $46.5 \%$ & $26.1 \%$ & $29.6 \%$ & $21.4 \%$ & & $29.2 \%$ & $25.0 \%$ & $31.1 \%$ & $30.9 \%$ \\
\hline & Number & 417 & 455 & 312 & 184 & 1947 & 295 & & 514 & 16 & 122 & 4262 \\
\hline$p$ & & ns & $* * *$ & ** & $\mathrm{ns}$ & $* * *$ & $* * *$ & $* * *$ & $* * *$ & * & ns & $* * *$ \\
\hline
\end{tabular}




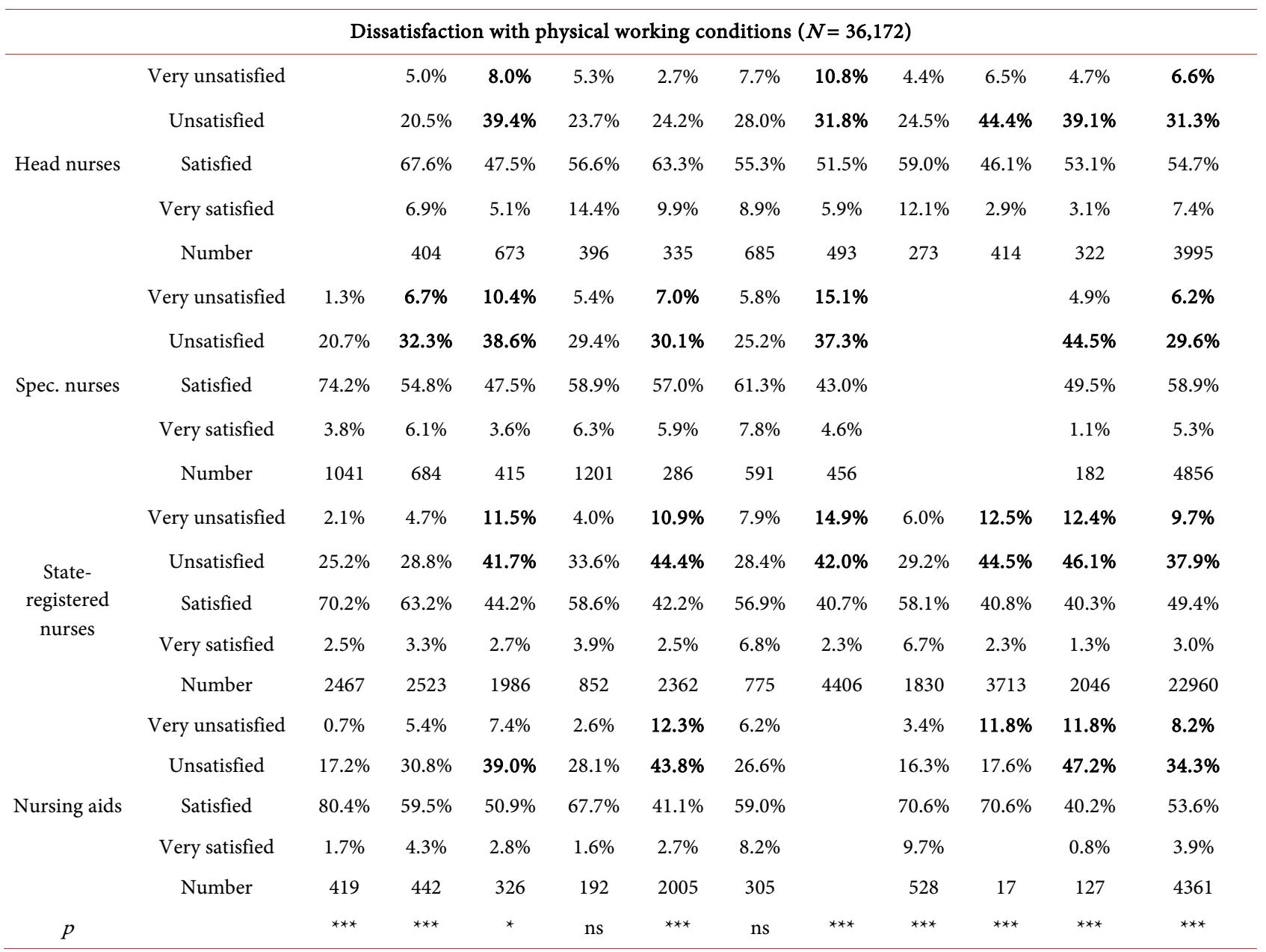

$p$-value: ${ }^{* *} p<0.001 ;{ }^{* *} p<0.01 ;{ }^{*} p<0.05$; ns is not significant. NL is the Netherlands; BE is Belgium; DE is Germany; FIN is Finland; FR is France; GB is Great Britain; IT is Italy; $N$ is Norway; POL is Poland; SLK is Slovakia.

reported to be "very unsatisfied", and $37.9 \%$ indicated to be "unsatisfied"), followed by the nursing aids (8.2\% "very unsatisfied", and 34.3\% "unsatisfied"). The head nurses and the specialized nurses reported somewhat less dissatisfaction with their physical working conditions: $6.6 \%$ of the head nurses appeared to be "very unsatisfied", and $31.3 \%$ "unsatisfied", while the outcomes were $6.2 \%$ "very unsatisfied", and 29.6\% "unsatisfied" for the specialized nurses (see Table 1 for specific outcomes).

Our data showed a clear pattern in the amount of physical load according to occupational level, with overall, higher scores reported by less qualified nurses. For the total sample, physical load was described to be "high" by $12.5 \%$ of the head nurses, by $14.1 \%$ of the specialized nurses, by $21.9 \%$ of the state-registered nurses, and by $29.5 \%$ of the nursing aids (see Table 2 for more specific outcomes). More specifically, for the total sample, work that is characterized by standing for 6 hours per day, and more, was reported by $34.4 \%$ of the head nurses, by $46.8 \%$ of the specialized nurses, by $57.2 \%$ of the state-registered nurses, and by $69.1 \%$ of the nursing aids. We have found similar outcomes for 
Table 2. Physical working conditions of nurses according to occupational level and country.

\begin{tabular}{|c|c|c|c|c|c|c|c|c|c|c|c|}
\hline Occupat & ional level & NL & $\mathrm{BE}$ & $\mathrm{DE}$ & FIN & FR & GB & IT & POL & SLK & Total \\
\hline \multicolumn{12}{|c|}{ Physical load (average of the sum score items) $(N=31,234)$} \\
\hline \multirow{3}{*}{ Head nurses } & Low or med. & & $91.5 \%$ & $71.9 \%$ & $86.2 \%$ & $98.6 \%$ & $91.3 \%$ & $97.3 \%$ & $84.0 \%$ & $90.8 \%$ & $87.5 \%$ \\
\hline & High & & $8.5 \%$ & $28.1 \%$ & $13.8 \%$ & $1.4 \%$ & $8.7 \%$ & $2.7 \%$ & $16.0 \%$ & $9.2 \%$ & $12.5 \%$ \\
\hline & Number & & 388 & 645 & 385 & 282 & 646 & 366 & 307 & 251 & 3270 \\
\hline \multirow{3}{*}{$\begin{array}{l}\text { Spec. } \\
\text { nurses }\end{array}$} & Low or med. & $86.1 \%$ & $86.1 \%$ & $76.6 \%$ & $87.8 \%$ & $85.5 \%$ & $86.8 \%$ & $85.1 \%$ & & $92.7 \%$ & $85.9 \%$ \\
\hline & High & $13.9 \%$ & $13.9 \%$ & $23.4 \%$ & $12.2 \%$ & $14.5 \%$ & $13.2 \%$ & $14.9 \%$ & & $7.3 \%$ & $14.1 \%$ \\
\hline & Number & 1018 & 676 & 401 & 1177 & 269 & 569 & 316 & & 165 & 4591 \\
\hline \multirow{3}{*}{$\begin{array}{l}\text { State- } \\
\text { registered } \\
\text { nurses }\end{array}$} & Low or med. & $85.3 \%$ & $84.6 \%$ & $65.7 \%$ & $81.1 \%$ & $83.1 \%$ & $88.9 \%$ & $80.0 \%$ & $68.3 \%$ & $72.2 \%$ & $78.1 \%$ \\
\hline & High & $14.7 \%$ & $15.4 \%$ & $34.3 \%$ & $18.9 \%$ & $16.9 \%$ & $11.1 \%$ & $20.0 \%$ & $31.7 \%$ & $27.8 \%$ & $21.9 \%$ \\
\hline & Number & 2443 & 2512 & 1959 & 847 & 2317 & 757 & 3974 & 3008 & 1871 & 19688 \\
\hline \multirow{3}{*}{$\begin{array}{l}\text { Nursing } \\
\text { aids }\end{array}$} & Low or med. & $90.0 \%$ & $70.4 \%$ & $64.0 \%$ & $75.9 \%$ & $65.8 \%$ & $78.6 \%$ & & $50.0 \%$ & $75.4 \%$ & $70.5 \%$ \\
\hline & High & $10.0 \%$ & $29.6 \%$ & $36.0 \%$ & $24.1 \%$ & $34.2 \%$ & $21.4 \%$ & & $50.0 \%$ & $24.6 \%$ & $29.5 \%$ \\
\hline & Number & 379 & 426 & 314 & 191 & 1935 & 290 & & 16 & 134 & 3685 \\
\hline$p$ & & * & $* * *$ & $* * *$ & $* * *$ & $* * *$ & $* * *$ & $* * *$ & $* * *$ & $* * *$ & $* * *$ \\
\hline \multicolumn{12}{|c|}{ Amount of hours standing at work per day $(\mathrm{N}=33,927)$} \\
\hline \multirow{5}{*}{ Head nurses } & $<4 \mathrm{hrs}$ & & $34.7 \%$ & $16.1 \%$ & $57.0 \%$ & $38.9 \%$ & $31.8 \%$ & $39.2 \%$ & $41.1 \%$ & $31.1 \%$ & $34.6 \%$ \\
\hline & $4-5 \mathrm{hrs}$ & & $29.5 \%$ & $35.7 \%$ & $20.4 \%$ & $36.8 \%$ & $22.5 \%$ & $37.0 \%$ & $34.4 \%$ & $34.1 \%$ & $31.0 \%$ \\
\hline & $6 \mathrm{hrs} \&+$ & & $35.9 \%$ & $48.2 \%$ & $22.6 \%$ & $24.3 \%$ & $45.7 \%$ & $23.8 \%$ & $24.5 \%$ & $34.7 \%$ & $34.4 \%$ \\
\hline & Number & & 404 & 670 & 393 & 334 & 683 & 495 & 436 & 331 & 3746 \\
\hline & $<4 \mathrm{hrs}$ & $30.1 \%$ & $9.7 \%$ & $6.2 \%$ & $38.6 \%$ & $9.4 \%$ & $24.5 \%$ & $33.7 \%$ & & $19.8 \%$ & $25.3 \%$ \\
\hline \multirow{4}{*}{$\begin{array}{l}\text { Spec. } \\
\text { nurses }\end{array}$} & $4-5 \mathrm{hrs}$ & $36.6 \%$ & $29.6 \%$ & $25.9 \%$ & $24.9 \%$ & $25.1 \%$ & $20.4 \%$ & $26.5 \%$ & & $29.1 \%$ & $27.9 \%$ \\
\hline & $6 \mathrm{hrs} \&+$ & $33.3 \%$ & $60.7 \%$ & $67.9 \%$ & $36.5 \%$ & $65.5 \%$ & $55.1 \%$ & $39.8 \%$ & & $51.1 \%$ & $46.8 \%$ \\
\hline & Number & 1039 & 693 & 417 & 1202 & 287 & 592 & 460 & & 182 & 4872 \\
\hline & $<4 \mathrm{hrs}$ & $27.5 \%$ & $9.6 \%$ & $6.7 \%$ & $21.5 \%$ & $9.4 \%$ & $18.1 \%$ & $9.5 \%$ & $17.4 \%$ & $18.0 \%$ & $14.3 \%$ \\
\hline \multirow{4}{*}{$\begin{array}{c}\text { State- } \\
\text { Registered } \\
\text { nurses }\end{array}$} & $4-5 \mathrm{hrs}$ & $36.1 \%$ & $41.7 \%$ & $28.7 \%$ & $28.4 \%$ & $22.0 \%$ & $22.3 \%$ & $26.9 \%$ & $23.9 \%$ & $24.0 \%$ & $28.4 \%$ \\
\hline & $6 \mathrm{hrs} \&+$ & $36.4 \%$ & $48.8 \%$ & $64.6 \%$ & $50.1 \%$ & $68.6 \%$ & $59.6 \%$ & $63.6 \%$ & $58.7 \%$ & $58.0 \%$ & $57.2 \%$ \\
\hline & Number & 2473 & 2553 & 1988 & 852 & 2377 & 779 & 4490 & 3817 & 2098 & 21427 \\
\hline & $<4 \mathrm{hrs}$ & $48.6 \%$ & $11.7 \%$ & $13.0 \%$ & $5.1 \%$ & $2.1 \%$ & $12.2 \%$ & & $17.6 \%$ & $10.4 \%$ & $10.5 \%$ \\
\hline \multirow{3}{*}{$\begin{array}{l}\text { Nursing } \\
\text { aids }\end{array}$} & $4-5$ hrs & $26.4 \%$ & $30.9 \%$ & $33.3 \%$ & $8.6 \%$ & $15.0 \%$ & $27.4 \%$ & & $29.4 \%$ & $17.0 \%$ & $20.4 \%$ \\
\hline & $6 \mathrm{hrs} \&+$ & $25.0 \%$ & $57.4 \%$ & $53.7 \%$ & $86.3 \%$ & $82.9 \%$ & $60.4 \%$ & & $52.9 \%$ & $72.6 \%$ & $69.1 \%$ \\
\hline & Number & 424 & 446 & 324 & 197 & 2036 & 303 & & 17 & 135 & 3882 \\
\hline$p$ & & $* * *$ & $* * *$ & $* * *$ & $* * *$ & $* * *$ & $* * *$ & $* * *$ & $* * *$ & $* * *$ & $* * *$ \\
\hline \multicolumn{12}{|c|}{ Uncomfortable postures $(N=31,008)$} \\
\hline \multirow{4}{*}{ Head nurses } & $0-5 /$ day & & $77.8 \%$ & $51.8 \%$ & $73.6 \%$ & $95.0 \%$ & $74.4 \%$ & $87.5 \%$ & $74.3 \%$ & $83.0 \%$ & $74.2 \%$ \\
\hline & $6-10 /$ day & & $15.1 \%$ & $21.6 \%$ & $15.8 \%$ & $3.2 \%$ & $15.7 \%$ & $5.4 \%$ & $12.9 \%$ & $9.5 \%$ & $13.8 \%$ \\
\hline & $>10 /$ day & & $7.0 \%$ & $26.6 \%$ & $10.6 \%$ & $1.8 \%$ & $9.9 \%$ & $7.1 \%$ & $12.9 \%$ & $7.5 \%$ & $12.0 \%$ \\
\hline & Number & & 383 & 643 & 387 & 282 & 645 & 368 & 311 & 253 & 3272 \\
\hline
\end{tabular}




\begin{tabular}{|c|c|c|c|c|c|c|c|c|c|c|c|}
\hline \multicolumn{12}{|l|}{ Continued } \\
\hline \multirow{4}{*}{$\begin{array}{l}\text { Spec. } \\
\text { nurses }\end{array}$} & $0-5 /$ day & $75.1 \%$ & $74.4 \%$ & $49.2 \%$ & $64.8 \%$ & $74.3 \%$ & $73.5 \%$ & \multicolumn{2}{|l|}{$74.7 \%$} & $80.0 \%$ & $70.0 \%$ \\
\hline & $6-10 /$ day & $15.8 \%$ & $14.6 \%$ & $24.6 \%$ & $20.3 \%$ & $14.9 \%$ & $16.0 \%$ & \multicolumn{2}{|l|}{$12.2 \%$} & $12.5 \%$ & $17.1 \%$ \\
\hline & $>10 /$ day & $9.2 \%$ & $10.9 \%$ & $26.1 \%$ & $14.9 \%$ & $10.8 \%$ & $10.4 \%$ & \multicolumn{2}{|l|}{$13.1 \%$} & $7.5 \%$ & $12.8 \%$ \\
\hline & Number & 1015 & 676 & 398 & 1180 & 269 & 567 & \multicolumn{2}{|l|}{320} & 160 & 4585 \\
\hline \multirow{4}{*}{$\begin{array}{l}\text { State- } \\
\text { registered }\end{array}$} & $0-5 /$ day & $75.8 \%$ & $72.4 \%$ & $43.5 \%$ & $60.0 \%$ & $66.7 \%$ & $68.4 \%$ & $62.4 \%$ & $56.7 \%$ & $70.2 \%$ & $63.9 \%$ \\
\hline & 6 - 10/day & $15.7 \%$ & $15.3 \%$ & $27.4 \%$ & $23.6 \%$ & $17.8 \%$ & $17.6 \%$ & $17.5 \%$ & $21.4 \%$ & $14.6 \%$ & $18.6 \%$ \\
\hline & $>10 /$ day & $8.5 \%$ & $12.4 \%$ & $29.1 \%$ & $16.4 \%$ & $15.5 \%$ & $14.0 \%$ & $20.1 \%$ & $21.9 \%$ & $15.2 \%$ & $17.5 \%$ \\
\hline & Number & 2440 & 2463 & 1953 & 845 & 2304 & 756 & \multirow[t]{5}{*}{3919} & 3016 & 1811 & 19,507 \\
\hline \multirow{4}{*}{$\begin{array}{l}\text { Nursing } \\
\text { aids }\end{array}$} & $0-5 /$ day & $84.4 \%$ & $67.2 \%$ & $52.9 \%$ & $57.1 \%$ & $55.5 \%$ & $63.9 \%$ & & $53.3 \%$ & $67.7 \%$ & $60.9 \%$ \\
\hline & $6-10 /$ day & $9.5 \%$ & $15.8 \%$ & $22.3 \%$ & $21.5 \%$ & $20.5 \%$ & $18.9 \%$ & & $26.7 \%$ & $20.5 \%$ & $18.9 \%$ \\
\hline & $>10 /$ day & $6.2 \%$ & $17.0 \%$ & $24.8 \%$ & $21.5 \%$ & $24.0 \%$ & $17.2 \%$ & & $20.0 \%$ & $11.8 \%$ & $20.3 \%$ \\
\hline & Number & 390 & 412 & 314 & 191 & 1910 & 285 & & 15 & 127 & 3644 \\
\hline$p$ & & $* * *$ & $* * *$ & $* * *$ & $* * *$ & $* * *$ & $* *$ & $* * *$ & $* * *$ & $* * *$ & $* * *$ \\
\hline
\end{tabular}

$p$-value: ${ }^{* *} p<0.001 ;{ }^{* *} p<0.01 ;{ }^{*} p<0.05$; NL is the Netherlands; BE is Belgium; DE is Germany; FIN is Finland; FR is France; GB is Great Britain; IT is Italy; $N$ is Norway; POL is Poland; SLK is Slovakia.

the amount of times the nurses had to work in uncomfortable postures, which were reported to be more than 10 times per day by $12.0 \%$ of the head nurses, by $12.8 \%$ of the specialized nurses, by $17.5 \%$ of the state-registered nurses, and by $20.3 \%$ of the nursing aids.

\subsection{Differences According to Employment Setting}

In order to better understand the possible influence of employment setting upon the prevalence of physical load, we will report some interesting findings in this regard (the reader may contact the second author for more details). In our sample $(N=39,898), 22.3 \%$ of the nurses working in hospitals reported a high physical load, compared with $32.2 \%$ of the nurses working in nursing homes, and $6.6 \%$ of the nurses working in home care. However, $44.4 \%$ of the nurses working in hospitals obtained a high Von Korff et al.'s (1992) disability score, compared with $48.1 \%$ in nursing homes, and $40.8 \%$ in home care. It is strikingly to find out that a relatively high percentage of nurses, across the occupational sectors already suffer from back- or neck-pain related disability scores, even although they perceived a relatively low physical load. However, a relatively low perceived physical load can be a very high risk factor, and eventually result into premature leave, in case the nurses work ability [reflected in a high Von Korff et al.'s (1992) disability score] is already at stake [2]. All the more reason to better understand the association between physical disability, and its determinants.

\subsection{Differences between European Countries}

In general, French, German, Italian, Polish, and Slovakian state-registered nurses declared more physical disabilities and MSDs in comparison with Belgian, Brit- 
ish, Dutch, and Finish ones. Moreover, they also appeared to be more often dissatisfied with their physical working conditions. In France, Germany, and Poland, in particular, it is clearly nursing aids that reported relatively high scores for physical load.

In the overall NEXT study [1], some striking differences across countries were observed as well and might add to our understanding of possible risk factors in the nursing profession. Concrete, nurses from the third-country cluster (Poland and Slovakia) reported a severe lack of lifting aids, serious lack of work-related opportunities in their own domestic region, and more frequent economic constraints. Obviously, their labour market decisions will be influenced by these factors, and, even in a situation wherein the nurse is very dissatisfied with the working conditions and (social) working environment, it is hard to obtain a more attractive alternative. Dutch nurses, on the other end of the continuum, reported the highest availability of lifting and bending aids, and the shortest work-week duration. Yet, still many of them consider premature leaving due to a perceived lack of challenges, health reasons, and a negative (social) working environment, to mention but a few reasons for turnover. For the Dutch nurses inadequate pay was not found to be a main reason to seriously consider leaving [1].

Moreover, the success of nurse migration (in East-West direction) seems to be limited [38]. Language problems and high attachment to their community in Eastern Europe might be some of the underlying reasons for this. On top of this, in many countries there are already only a few nurses who are active in their profession until normal retirement age. All in all, therefore, it seems to be extremely important to continue cross-national comparisons as the retention of nursing staff across Europe is more important than ever.

\subsection{Multivariate Analysis of Factors Linked with Back- or Neck-Pain-Related Disability}

In order to determine the effect of different risk factors in the light of back- or neck-pain-related disability, binary logistic regression analyses have been performed (see Table 3). For sake of parsimoniousness, we will only report the outcomes for the total sample of nurses. The analyses by country and type of health care institution largely confirmed these findings with a high degree of consistency [see also 10]. We can clearly conclude that it is the amount of physical load, as indicated by the "physical load major factors in nursing" index, and the quality of teamwork that are major determinant factors, and not the occupational level itself. We observed an exposure-outcome gradient for these specific risk factors. Nurses reporting medium and high physical load more often reported high back- or neck-pain-related disability scores compared with those reporting a low physical load (medium adjOR $=1.25$; 95\% CI $1.15-1.35$; high $\operatorname{adjOR}=1.75$; 95\% CI 1.61 - 1.91).

Those nurses who expressed to be considerably dissatisfied with their physical working conditions more frequently showed a high back- or neck-pain-related 
Table 3. Factors associated with high back- and neck-pain-related disability score, and with musculoskeletal disorders among nurses.

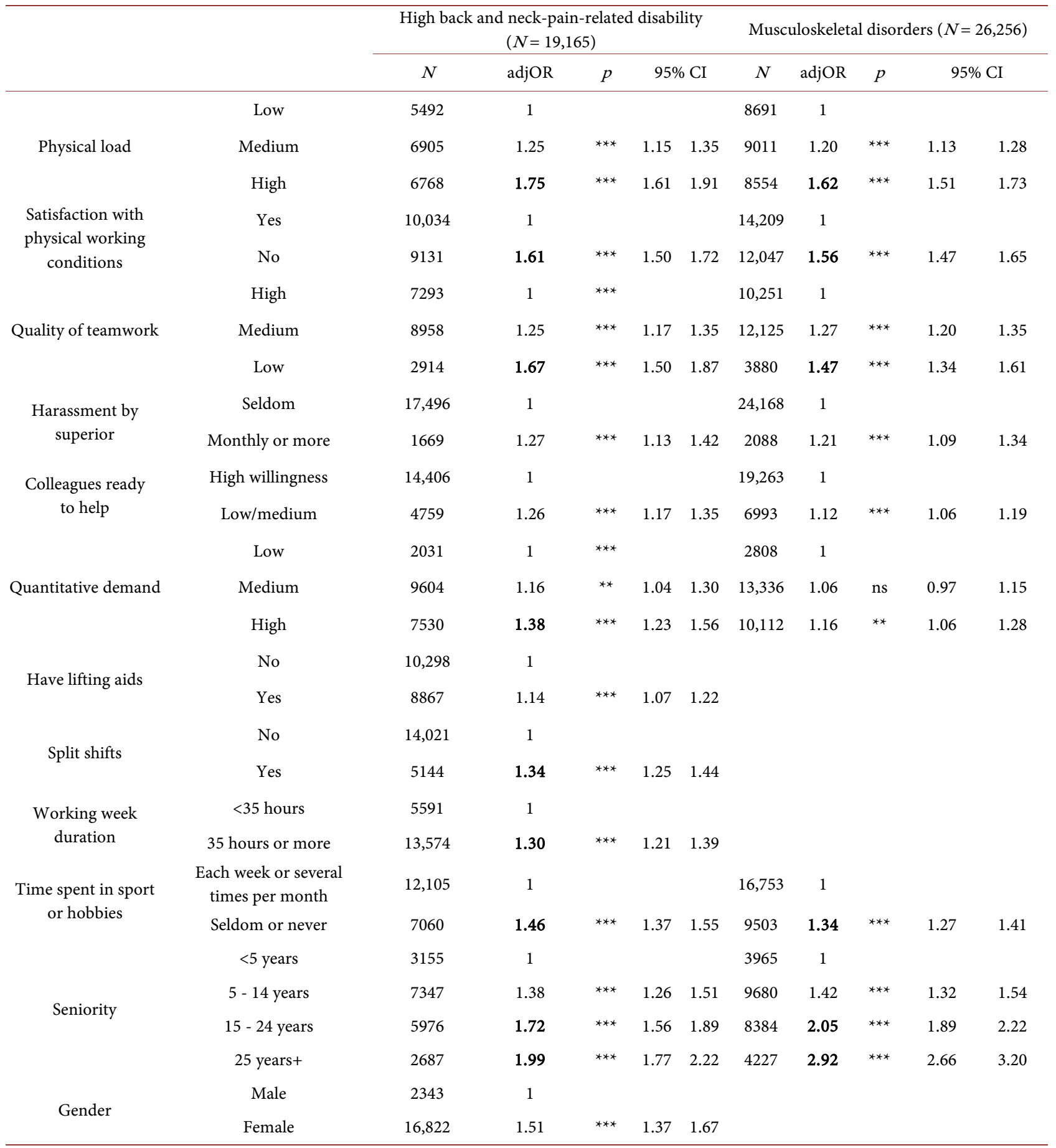

(1) For both types of analysis, family situation, age and occupational level were removed in case of no significance when adjusted for other risk factors. All the significant variables in bivariate analysis were included in the multivariate model and removed, step by step, when non-significant. $p$-value: ${ }^{* *} p<0.001$; ${ }^{* *} p<0.01 ;{ }^{*} p<0.05 ;$ ns is not significant.

disability score (adjOR $=1.61 ; 95 \%$ CI 1.50 - 1.72). More specifically, nurses reporting not having lifting aids available more frequently showed a high back- or neck-pain-related disability score $($ adjOR $=1.14 ; 95 \%$ CI 1.07 - 1.22). Nurses 
who indicated medium or low quality of teamwork more often reported high back- or neck-pain-related disability scores compared with those with high quality teamwork (medium adjOR $=1.25 ; 95 \%$ CI $1.17-1.35$; low adjOR $=1.67 ; 95 \%$ CI 1.50 - 1.87).

Our study also indicated that some other personal factors and (social) working conditions appear to have influence upon nurses' back- or neck-pain-related disability, namely a high quantitative work demand, having to work in split shifts, having a full-time job, colleagues not (quite) ready to help, and harassment by superiors. Nurses declaring a high quantitative work demand more frequently reported high back- or neck-pain-related disability scores $(\mathrm{OR}=1.38$; $95 \%$ CI 1.23 - 1.56). Nurses who indicated having to work in split shifts more often reported high back- or neck-pain-related disability scores ( $\mathrm{OR}=1.34 ; 95 \%$ CI 1.25 - 1.44). Working part-time appeared to be an important buffer as nurses who reported to work at least 35 hours per week appeared to have higher backor neck-pain-related disability scores $(\mathrm{OR}=1.30 ; 95 \% \mathrm{CI} 1.21$ - 1.39). Moreover, nurses' (social) working environment appeared to be important, as nurses who indicated that their colleagues were not (quite) ready to help, more frequently reported high back- or neck-pain-related disability scores as well $(\mathrm{OR}=1.26$; 95\% CI 1.17 - 1.35), while, in a similar vein, nurses who declared to be the victim of harassment by their superior showed higher back- or neck-pain-related disability scores (OR $=1.27$; 95\% CI $1.13-1.42)$.

The practice of sports and/or hobbies is a factor which appeared to buffer the negative impact of physical load (OR = 1.46; 95\% CI 1.37 - 1.55 for "no sports and/or hobbies" as opposed to "activities practised weekly"). Also, seniority appeared to have a major influence (adjOR $=1.99 ; 95 \%$ CI $1.77-2.22$ for those of 25 years of seniority or more, but with a clear exposure-outcome gradient starting at 5 years of seniority). Finally, female nurses more often reported high backor neck-pain-related disability scores compared with their male counterparts.

\subsection{Multivariate Analysis of Factors Linked with Musculoskeletal Disorders}

Additionally, binary logistic regression analyses were performed in order to determine the effect of different risk factors in the light of declaration of MSDs (see Table 3). For sake of parsimoniousness, we will only report the outcomes for the total sample of nurses. The analysis by country and type of health care institution largely confirmed these findings with a high degree of consistency (see also [10]). Again, we can clearly conclude that it is the amount of physical load, as indicated by the "physical load major factors in nursing" index, and the quality of teamwork that are major determinant factors, and not the occupational level itself. We observed a clear exposure-outcome gradient for these risk factors. Nurses describing medium and high physical load more often reported MSDs compared with those with a low physical load (medium adjOR $=1.20$; $95 \% \mathrm{CI}$ 1.13 - 1.28; high adjOR $=1.62$; 95\% CI 1.51 - 1.73). Moreover, nurses who expressed to be considerably dissatisfied with their physical working conditions 
more frequently showed MSDs (adjOR = 1.56; 95\% CI 1.47 - 1.65). And nurses describing medium or low quality of teamwork more often reported MSDs compared with those reporting high quality of teamwork (medium adjOR = 1.27; 95\% CI 1.20 - 1.35; low adjOR = 1.47; 95\% CI 1.34 - 1.61).

Our outcomes also confirmed our earlier analyses indicating the importance of some personal factors and (social) working conditions in this regard, namely a high quantitative work demand, having colleagues not (quite) ready to help, and harassment by superiors. Again, the practice of sports and/or hobbies appeared to be a factor which can buffer the negative impact of physical load. Also, seniority appeared to have a major influence (adjOR $=2.92$; 95\% CI $2.66-3.20$ for those of 25 years of seniority or more, but with a clear exposure-outcome gradient starting at 5 years of seniority). Other factors appeared not to be significant for MSDs and were removed step by step during the analysis.

\subsection{Factors Associated with Back- and Neck-Pain-Related Disability Scores by Age Group}

It appears that physical load increasingly explains a high back- or neck-pain-related disability score with older age (see Table 4 for more specific outcomes). In all age groups, nurses more often reported a high back- or neck-pain-related disability score when they experienced a high physical load $(\mathrm{OR}=1.77$ among nurses under 30 years, $\mathrm{OR}=1.72$ among nurses between 30 to 44 years, and OR $=1.88$ among nurses of 45 years or more; $p<0.001$ for each age group). Moreover, across all age groups, nurses more often reported a relatively high back- or neck-pain-related disability score when they were dissatisfied with their physical working conditions, in particular the older ones $(\mathrm{OR}=1.62$ among nurses under 30 years, $\mathrm{OR}=1.56$ among nurses between 30 to 44 years, and $\mathrm{OR}=1.81$ among nurses of 45 years or more; $p<0.001$ for each age group). Nurses reporting not having lifting aids available more frequently showed a high back- or neck-pain-related score $(\mathrm{OR}=1.21$ among nurses under 30 years, $\mathrm{OR}=1.18$ among nurses between 30 to 44 years). This factor appeared not to be significant for older nurses.

Nurses declaring a high quantitative work demand more frequently reported high back- or neck-pain-related disability scores, even more so for the younger ones $(\mathrm{OR}=1.60$ among nurses under 30 years, $\mathrm{OR}=1.29$ among nurses between 30 to 44 years, and $\mathrm{OR}=1.32$ for the nurses of 45 years or more; $p<0.01$ for each age group).

It also appeared that some (social) working conditions increasingly explained a high back- or neck-pain-related disability score with older age. More specifically, the role of the quality of teamwork in the light of physical disability appeared to become more important with age. Nurses more often reported a high back- or neck-pain-related disability score when their quality of teamwork score was perceived to be low $(\mathrm{OR}=1.62$ among nurses under 30 years, $\mathrm{OR}=1.65$ among nurses between 30 to 44 years, and OR $=1.81$ among nurses of 45 years or more; $p<0.001$ for each age group). Nurses who reported that their colleagues 
Table 4. Multivariate analysis of factors associated with back- and neck-pain-related disability scores by age group.

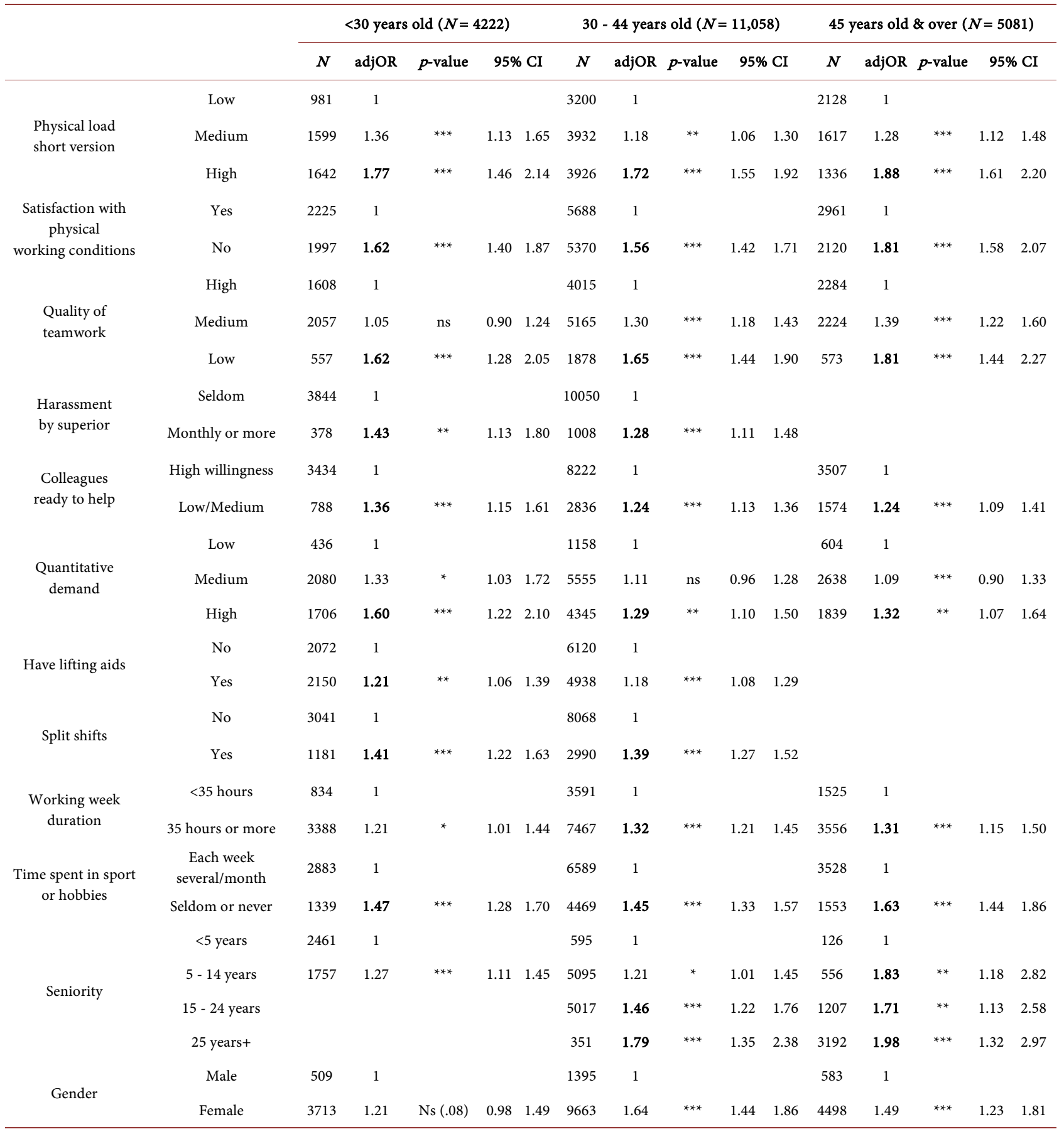

$p$-value: ${ }^{* *} p<0.001 ;{ }^{* *} p<0.01 ;{ }^{*} p<0.05 ;$ ns is not significant.

are not (quite) ready to help them showed a relatively high back- or neck-pain-related disability score, even more so before the age of $30(\mathrm{OR}=1.36$ among nurses under 30 years, $\mathrm{OR}=1.24$ among nurses aged 30 to 44 years, and $\mathrm{OR}=1.24$ among nurses aged 45 years or more). Harassment by one's superior is a significant factor in the light of explaining the experience of physical load among nurses under 30 years $(\mathrm{OR}=1.43)$, and among nurses between 30 to 44 
years $(\mathrm{OR}=1.28)$.

Working part-time appeared to be an important buffer $(\mathrm{OR}=1.21$ for nurses under the age of 30 with a work week of 35 hours or more, compared to the baseline comprising nurses in part-time employment, $\mathrm{OR}=1.32$ among nurses between 30 to 44 years, and $\mathrm{OR}=1.31$ among nurses of 45 years or more; $p<$ 0.001 for the two older age groups). Moreover, nurses who indicated having to work in split shifts more often reported high back- or neck-pain-related disability scores $(\mathrm{OR}=1.41$ among nurses under 30 years, $\mathrm{OR}=1.39$ among nurses between 30 to 44 years). This factor was not significant for older nurses, who are also less frequently concerned by this type of work.

Finally, the practice of sports and/or hobbies appeared to have a protective function as well, and may reduce the impact of physical load for nurses in all age groups $(\mathrm{OR}=1.47$ for nurses under 30 years, $\mathrm{OR}=1.45$ for nurses between 30 to 44 years, and $\mathrm{OR}=1.63$ for the nurses 45 years or older; $p<0.001$ for "no sports and/or hobbies" as opposed to "activities practised weekly").

Occupational level was not a significant predictor of prevalence of back- or neck-pain-related disability. Our study indicates that it is the physical working conditions which make the difference. Meanwhile, seniority appears to be a major factor in all age groups. Nurses with 5 - 14 years of seniority more often reported a high back- or neck-pain-related disability score compared with nurses with less than 5 years of seniority across all age groups, even for nurses under 30 years old. We observed an exposure-outcome gradient, with longer exposure due to seniority among nurses between 30 to 44 years $(\mathrm{OR}=1.21$ among nurses with $5-14$ years of seniority, $\mathrm{OR}=1.46$ among nurses between 15 to 24 years, and OR $=1.79$ among nurses 25 years of seniority or more; $p<0.001$ ). For nurses of 45 years or older, a high score for back- or neck-pain-related disability is already quite frequent after 5 years of seniority $(\mathrm{OR}=1.83$ compared to nurses with less than 5 years of seniority), and appears to increase with more seniority (OR = 1.98).

Finally, across the distinguished age groups, female nurses more often reported high back- or neck-pain-related disability scores compared with their male colleagues.

\subsection{Factors Associated with Back- and Neck-Pain-Related Disability Scores by Occupational Level}

From Table 5, it appears that physical working conditions explain a high backor neck-pain-related disability score in about the same magnitude across occupational levels. However, nursing aids and state-registered nurses are more likely to be exposed than specialized nurses and head nurses.

In all occupational level groups, nurses reported nearly twice as much a high back- or neck-pain-related disability score when they experienced a high physical load $(\mathrm{OR}=1.90$ among head nurses, $\mathrm{OR}=1.63$ among specialized nurses, $\mathrm{OR}=1.68$ among state-registered nurses and $\mathrm{OR}=1.95$ among nursing aids; $p<$ 0.001 for each occupational level group). For all occupational level categories, 
Table 5. Multivariate analysis for factors associated with back- and neck-pain-related disability scores by occupational level.

\begin{tabular}{|c|c|c|c|c|c|c|c|c|c|c|c|c|c|c|c|c|c|c|c|c|c|}
\hline & & \multicolumn{5}{|c|}{ Head nurses $(N=2031)$} & \multicolumn{5}{|c|}{$\begin{array}{l}\text { Specialized nurses } \\
\qquad(N=2596)\end{array}$} & \multicolumn{5}{|c|}{$\begin{array}{l}\text { State-registered nurses } \\
\qquad(N=12,243)\end{array}$} & \multicolumn{5}{|c|}{ Nursing aids $(N=2315)$} \\
\hline & & $N$ & adjOR & $p$ & $95 \%$ & $6 \mathrm{CI}$ & $N$ & $\operatorname{adjOR}$ & $p$ & $95 \%$ & $\% \mathrm{CI}$ & $N$ & adjOR & $p$ & $95 \%$ & $6 \mathrm{CI}$ & $N$ & adjOR & $p$ & $95 \%$ & $\%$ CI \\
\hline \multirow{3}{*}{ Physical load } & Low & 1157 & 1 & & & & 902 & 1 & & & & 3317 & 1 & & & & 487 & 1 & & & \\
\hline & Medium & 486 & 1.11 & ns & 0.88 & 1.39 & 990 & 1.08 & ns & 0.87 & 1.34 & 4484 & 1.25 & $* * *$ & 1.13 & 1.39 & 841 & 1.40 & $* *$ & 1.10 & 1.78 \\
\hline & High & 388 & 1.90 & $* * *$ & 1.47 & 2.45 & 704 & 1.63 & $* * *$ & 1.28 & 2.08 & 4442 & 1.68 & $* * *$ & 1.51 & 1.87 & 987 & 1.95 & $* * *$ & 1.53 & 2.49 \\
\hline \multirow{3}{*}{$\begin{array}{l}\text { Satisfaction with } \\
\text { physical working } \\
\text { conditions }\end{array}$} & Yes & 1251 & 1 & & & & 1633 & 1 & & & & 6086 & 1 & & & & 1176 & 1 & & & \\
\hline & No & 780 & 1.46 & $* * *$ & 1.18 & 1.80 & 963 & 1.70 & $* * *$ & 1.40 & 2.07 & 6157 & 1.59 & $* * *$ & 1.46 & 1.74 & 1139 & 2.02 & $* * *$ & 1.68 & 2.42 \\
\hline & High & 845 & 1 & & & & 1135 & 1 & & & & 4407 & 1 & & & & & & & & \\
\hline $\begin{array}{l}\text { Quality of } \\
\text { teamwork }\end{array}$ & Medium & 929 & 1.50 & $* * *$ & 1.22 & 1.86 & 1176 & 1.29 & * & 1.05 & 1.58 & 5761 & 1.29 & $* * *$ & 1.18 & 1.42 & & & & & \\
\hline \multirow{2}{*}{$\begin{array}{l}\text { Harassment } \\
\text { by superior }\end{array}$} & Seldom & & & & & & & & & & & 11128 & 1 & & & & 2119 & 1 & & & \\
\hline & Monthly or more & & & & & & & & & & & 1115 & 1.24 & ** & 1.08 & 1.42 & 196 & 2.26 & $* * *$ & 1.60 & 3.19 \\
\hline \multirow{2}{*}{$\begin{array}{l}\text { Colleagues ready } \\
\text { to help }\end{array}$} & High willingness & & & & & & 2045 & 1 & & & & 3529 & 1 & & & & & & & & \\
\hline & Low/medium & & & & & & 551 & 1.33 & $* *$ & 1.07 & 1.64 & 2864 & 1.26 & $* * *$ & 1.15 & 1.38 & & & & & \\
\hline \multirow{3}{*}{$\begin{array}{l}\text { Quantitative } \\
\text { demand }\end{array}$} & Low & 148 & 1 & & & & 282 & 1 & & & & 1285 & 1 & & & & & & & & \\
\hline & Medium & 1012 & 1.17 & ns & 0.79 & 1.73 & 1478 & 1.65 & ** & 1.16 & 2.34 & 6048 & 1.17 & * & 1.02 & 1.34 & & & & & \\
\hline & High & 871 & 1.52 & * & 1.02 & 2.28 & 836 & 1.91 & $* * *$ & 1.31 & 2.78 & 4910 & 1.39 & $* * *$ & 1.20 & 1.62 & & & & & \\
\hline \multirow{2}{*}{ Have lifting aids } & Yes & & & & & & & & & & & 6960 & 1 & & & & & & & & \\
\hline & No & & & & & & & & & & & 5283 & 1.21 & $* * *$ & 1.11 & 1.31 & & & & & \\
\hline Split shifts & Yes & & & & & & 379 & 1.34 & * & 1.05 & 1.70 & 8714 & 1.31 & $* * *$ & 1.21 & 1.43 & 850 & 1.28 & $* *$ & 1.07 & 1.53 \\
\hline \multirow{2}{*}{$\begin{array}{l}\text { Working week } \\
\text { duration }\end{array}$} & $<35$ hours & 190 & 1 & & & & 1061 & 1 & & & & 3605 & 1 & & & & & & & & \\
\hline & 35 hours or more & 1841 & 1.42 & * & 1.03 & 1.96 & 1535 & 1.27 & ** & 1.05 & 1.53 & 8638 & 1.24 & $* * *$ & 1.13 & 1.36 & & & & & \\
\hline \multirow{3}{*}{ Department } & Other & & & & & & & & & & & 8537 & 1 & & & & & & & & \\
\hline & Medico-surgical units & & & & & & & & & & & 2498 & 1.03 & ns & 0.94 & 1.14 & & & & & \\
\hline & Geriatric care & & & & & & & & & & & 1208 & 1.29 & $* * *$ & 1.13 & 1.47 & & & & & \\
\hline \multirow{2}{*}{$\begin{array}{l}\text { Time spent in } \\
\text { sport or hobbies }\end{array}$} & Each week sev./month & 1300 & 1 & & & & 2068 & 1 & & & & 7274 & 1 & & & & 1302 & 1 & & & \\
\hline & Seldom or never & 731 & 1.59 & $* * *$ & 1.31 & 1.92 & 528 & 1.55 & $* * *$ & 1.26 & 1.91 & 4969 & 1.43 & $* * *$ & 1.32 & 1.55 & 1013 & 1.52 & $* * *$ & 1.28 & 1.82 \\
\hline \multirow{4}{*}{ Seniority } & $<5$ years & & & & & & & & & & & 2162 & 1 & & & & 508 & 1 & & & \\
\hline & 5 - 14 years & & & & & & & & & & & 4936 & 1.34 & $* * *$ & 1.20 & 1.50 & 861 & 1.50 & $* * *$ & 1.19 & 1.89 \\
\hline & 15 - 24 years & & & & & & & & & & & 3728 & 1.76 & $* * *$ & 1.56 & 1.98 & 602 & 1.86 & $* * *$ & 1.44 & 2.40 \\
\hline & 25 years + & & & & & & & & & & & 1417 & 1.99 & $* * *$ & 1.72 & 2.30 & 344 & 2.52 & $* * *$ & 1.87 & 3.38 \\
\hline \multirow{3}{*}{ Age } & $<30$ years old & & & & & & 462 & 1 & & & & & & & & & & & & & \\
\hline & $30-45$ years old & & & & & & 1555 & 1.61 & $* * *$ & 1.25 & 2.07 & & & & & & & & & & \\
\hline & $>45$ years old & & & & & & 579 & 1.84 & $* * *$ & 1.38 & 2.46 & & & & & & & & & & \\
\hline \multirow{2}{*}{ Gender } & Male & 330 & 1 & & & & 385 & 1 & & & & 1499 & 1 & & & & 189 & 1 & & & \\
\hline & Female & 1701 & 1.50 & $* *$ & 1.16 & 1.94 & 2211 & 1.40 & $* *$ & 1.08 & 1.81 & 10744 & 1.52 & $* * *$ & 1.34 & 1.71 & 2126 & 1.76 & $* * *$ & 1.27 & 2.43 \\
\hline
\end{tabular}

$p$-value: ${ }^{* * *} p<0.001 ;{ }^{* *} p<0.01 ;{ }^{*} p<0.05$; ns is not significant. 
nurses more often reported a high back- or neck-pain-related disability score when they were dissatisfied with their physical working conditions $(\mathrm{OR}=1.46$ among head nurses, $\mathrm{OR}=1.70$ among specialized nurses, $\mathrm{OR}=1.59$ among state-registered nurses and $\mathrm{OR}=2.02$ among nursing aids; $p<0.001$ for each occupational level group). Moreover, state-registered nurses reporting not having lifting aids available more frequently showed a high back- or neck-pain-related disability score $(\mathrm{OR}=1.21)$.

Nurses declaring a high quantitative work demand more frequently reported high back- or neck-pain-related disability scores [OR $=1.52$ among head nurses $(p<0.05), \mathrm{OR}=1.91$ among specialized nurses $(p<0.01)$ and $\mathrm{OR}=1.39$ among state-registered nurses $(p<0.001)]$. This is not significant for nursing aids as they are very few in the low quantitative demand group.

Quality of team work appeared to be an important buffer to reduce back- or neck-pain-related disability for nurses from all occupational levels, but it appeared not to be of importance for nursing aids, for whom it is probably the physical load itself which is a stronger determinant. More specifically, nurses more often reported a high back- or neck-pain-related disability score when their quality of teamwork score was perceived to be low $(\mathrm{OR}=1.83$ among head nurses, $\mathrm{OR}=1.99$ among specialized nurses and $\mathrm{OR}=1.71$ among state-registered nurses; $p<0.001$ for each occupational level group).

Nurses who reported that their colleagues are not (quite) ready to help them showed a relatively higher back- or neck-pain-related disability score, yet only for specialized and state-registered nurses (OR $=1.33$ among specialized nurses, $\mathrm{OR}=1.26$ among state-registered nurses; $p<0.001$ for each occupational level group). Harassment by one's superior is a significant factor in the light of explaining the experience of physical load among state-registered nurses $(\mathrm{OR}=$ $1.24)$, and among nursing aids $(\mathrm{OR}=2.26)$.

Working part-time appeared to be an important buffer for nurses with a work week of 35 hours or more, compared to the baseline comprising nurses in part-time employment, $(\mathrm{OR}=1.42$ among head nurses, $\mathrm{OR}=1.27$ among specialized nurses and $\mathrm{OR}=1.24(p<0.001)$ among state-registered nurses; $p<0.01$ for the first two occupational level group). Nurses who indicated having to work in split shifts more often reported high back- or neck-pain-related disability scores $(\mathrm{OR}=1.34$ among specialized nurses, $\mathrm{OR}=1.31(p<0.001)$ among state-registered nurses and $\mathrm{OR}=1.28$ among nursing aids; $p<0.01$ for specialized nurses and nursing aids). This factor was not significant for head nurses, probably being less frequently concerned by this type of work.

Finally, the practice of sports and/or hobbies appeared to have a protective function as well, and may reduce the impact of physical load for nurses in all occupational level groups $(\mathrm{OR}=1.59$ among head nurses, $\mathrm{OR}=1.55$ among specialized nurses and $\mathrm{OR}=1.43$ among state-registered nurses and $\mathrm{OR}=1.52$ among nursing aids; $p<0.001$ for "no sports and/or hobbies" as opposed to "activities practised weekly").

From the outline given above, all in all, we may conclude that, in general, the 
risk of physical disability is positively associated with the amount of physical load and the nurses' dissatisfaction with this, with a lack of teamwork quality, harassment by supervisors, colleagues not (quite) ready to help, not having lifting aids, a high quantitative work demand, and having to work in split shifts. In addition, we have found that the main moderating or buffering factors in this regard are having a part-time job, practice of sport and/or hobbies, and the nurses' social work environment.

\section{Reflection upon the Outcomes}

This study was meant to partly close the gap of empirical research aimed at a better understanding of prevalence of, and risk factors for, physical disability among nurses working in different occupational levels and in different health care settings. Only in case we carefully pay attention to possible differences across occupational groups, we can more safely conclude on the generalizability of the outcomes, and/or whether tailor-made approaches to prevent risks for physical disability ought to be undertaken. A particular strength of this empirical work is the large sample size and the diverse nature of the sample, including nurses working at different occupational levels, from across Europe, and sampled across hospitals, nursing homes, and home care institutions.

Our results showed that physical disability (i.e. back- and neck-pain-related disability and MSDs) increases with the amount of physical load and the nurses' dissatisfaction with this, a lack of teamwork quality, harassment by supervisors, colleagues not (quite) ready to help, not having lifting aids, a high quantitative work demand, and having to work in split shifts. The main buffering factors addressed in this study are having a part-time job, practice of sport and/or hobbies, and the nurses' (social) working environment.

As regards differences across age groups, we have found that with ageing, nurses appear to suffer more, in terms of increased back- or neck-related disability, in case they experience a high physical load and dissatisfaction with their physical working conditions. Physical working conditions appear to explain a high back- or neck-related disability score in about the same magnitude across occupational levels; with nursing aids and state-registered nurses being more likely to be exposed in comparison with specialized nurses and head nurses.

Moreover, it appeared that (social) working conditions were associated with physical disability, with interesting differences across the age groups and across occupational sectors. These outcomes imply that management in healthcare organizations should take age and occupational sector explicitly into account when trying to prevent physical disability (see also [39]).

As those professionals working in nursing are exposed to emotional involvement, stress and work constraints, the need for talking things through with colleagues and supervisors is strongly apparent [40]. When it comes to situations of psychological stress, colleagues appear to be the most important source of support, particularly when institutionally [by means of a highly supportive direct supervisor or other members of the management team, lifting and bending tech- 
niques (see also [41]), and possibilities to roster flexibly, to give some examples] that kind of support is lacking (see also [42]). The next study has indicated (see [1]) that many nurses perceive the institutional support mechanisms as inadequate and not supportive in practice, and seriously consider to leave their institution and/or, even worse, to leave their profession. This situation is severe as the pressure on the health care sector is only expected to increase over the years to come [43]. Obviously, in the light of the demographic chances and the deteriorating image of the nursing profession, retention of nursing staff requires our full attention.

Our study indicates that in case thorough attention is paid to one's (social) work environment, characterized by a supportive team climate and a supportive supervisor, and in particular to the employability of older nursing staff and nursing aids, physical disability may be prevented. In a time wherein many countries are striving to increase retirement age, it is especially important to protect nursing staff across the life-span.

The outcomes of our study are important as they shed more light on the relationship between one's work situation and social support and other possibly buffering mechanisms, on the one hand, and physical disability, on the other hand. In a critical review based upon a meta-analysis of 40 studies, made by Hartvigsen, Christensen, and Frederiksen (2003), it was concluded that there is moderate evidence for the absence of a significant relationship [44]. Our results, based on a large European sample, allow us to conclude otherwise. That is to say, we have found empirical support for quite a strong association between perceptions of physical working conditions and (social) work environment, on the one hand, and physical disability, on the other hand. In general, the relationships were particularly strong for older nurses and for nursing aids.

Moreover, our results are in line with the outcomes of previous research by Eriksen, Bruusgaard, and Knardahl (2004) and by IJzelenberg and Burdorf (2004) [19] [27]. Additionally, our group comparisons reconfirm their outcomes across occupational groups (head nurses, specialized and state-registered nurses as well as for nursing aids) working in different health care institutions (hospitals, nursing homes, and home care), herewith supporting the generalizability of the effects that were found.

Hignett (2003) showed that only multi-faceted interventions with better teamwork and anti-lifting policy resulted in a considerable reduction in MSDs [45]. In line with this, based on the results from our study, we are able to conclude that it is clearly necessary to both alleviate physical load, and to optimize one's (social) working environment in order to retain healthy aging nurses. Moreover, sports and hobbies should be more widely practiced as they appear to lead to a better work ability, i.e. a better physical and mental health [2], and may help to prevent premature leave. Female nurses with irregular working hours especially have difficulties to practice sports and hobbies, and it is highly necessary to facilitate them in order to enable them to stay healthy.

It is of utmost importance to improve nurses' physical working conditions 
and social working environment, not only in order to improve their quality of life, but also in order to prevent that employers are left with more and more nursing staff with physical disability, while losing those nurses who are (still) healthy. Nurses who have been exposed to an excessively high physical load, for an extended period of time, do not have any opportunities other than to stay in their current profession, since they are in many occasions already manifestly suffering from work-related back- and neck-pain-related disability and MSDs. Moreover, the public health sector, employing the majority of nurses in most European countries, offers opportunities to remain fully paid when on sick leave. As no future employer would hire them, they remain in their current employment without putting effort in changing their working life situation.

\section{Recommendations for Future Research}

We call for more, and preferably longitudinal, research wherein both personal, and organizational factors are taken into account, yet, complemented with the impact of labour market circumstances. Only if we are able to fully understand to what extent labour market circumstances allow nurses to freely decide on career choices can the detrimental effects of physical disability, and its determinants, be more clearly understood. As nurses' dominant work orientation is based upon the fundamental concern for patients' welfare, it is important to continuously watch over their physical ability, as it is not inconceivable that some nurses will continue working, even in case of severe health problems, herewith endangering their future employability. It is hard to understand why, in a period of huge nurse shortages, their life-long employability receives such poor guidance [46]. After all, it is not only the amount of respect and recognition by head nurses, doctors, and administrators, to mention but a few parties, that is at stake here. Many of the nurses in our sample reported that their job is highly physically demanding, and thus already endangering their current career potential (see also [47]).

Moreover, given the importance of improving nurses' physical and social working environment, especially in an era of huge shortages of nurses, we call for more research that goes into a better understanding of those particular factors of the work environment that explain their (dis)satisfaction. The commonly used broad operationalizations for workplace-related satisfaction measures ought to be complemented with in-depth semi-structured interviews aimed at supporting the outcomes of quantitative research with qualitative outcomes referring to underlying causes. In addition, participatory ergonomic interventions could be conducted aimed at a better understanding of how working space and equipment interact in situations of working in awkward positions, prolonged standing, and lifting heavy loads. Also, as this study is fully based on self-reported data, future work incorporating multi-source ratings will add to our knowledge.

\section{Conclusion}

In health care organizations that cannot provide adequate (career) support, 
working practice in this occupational sector will produce widening gaps between the demand for and supply of such support. Managers that fail to discover such deficiencies in good time will experience growing levels of dissatisfaction and disability that might result in premature leave, reduced productivity or higher absenteeism (see also [48] [49]). If the nature of the deficiencies is only slight, job satisfaction and morale are reduced [50]. If it is more serious, turnover intentions will increase, impacting upon corporate growth and long-term performance [51].

\section{Relevance to Clinical Practice}

Today, there is a substantial shortage of nurses in Europe, and demographic changes in the coming years might worsen this situation if no action is taken. Management in healthcare organizations that fails to improve physical working conditions and to provide adequate (career) support, will experience growing levels of disability and dissatisfaction among nursing staff that might result in premature leave, reduced productivity or higher absenteeism.

\section{What Does This Paper Contribute to the Wider Global Clinical Community?}

- Both personal, physical and (social) work environmental factors, that might cause physical disability of nurses and nursing aids, are examined using a large-scale study.

- If management in health care organizations ignores problems related to physical disability, job satisfaction and morale are reduced, and in serious cases, turnover intentions will increase, herewith impacting long-term performance of the specific institutions.

- Given the demographic changes, it is urgent to take measures in order to prevent further shortages of nurses and nursing aids.

\section{Conflicts of Interest}

The authors declare no conflicts of interest regarding the publication of this paper.

\section{References}

[1] Hasselhorn, H., Tackenberg, P. and Müller, B. (2003) Working Conditions and Intent to Leave the Profession among Nurses Staff in Europe. Report No. 7. A Research Project Initiated by SALTSA (Joint Programme for Working Life Research in Europe) and Funded by the European Commission (QLK6-CT-2001-00475).

[2] Ilmarinen, J. (1999) Ageing Workers in the European Union-Status and Promotion of Work Ability, Employability and Employment. Finnish Institute of Occupational Health, Helsinki.

[3] Fugate, M., Kinicki, A.J. and Ashforth, B.E. (2004) Employability: A Psycho-Social Construct, Its Dimensions and Applications. Journal of Vocational Behavior, 65, 14-38. https://doi.org/10.1016/j.jvb.2003.10.005 
[4] Van der Heijde, C.M. and Van der Heijden, B.I.J.M. (2006) A Competence-Based and Multidimensional Operationalization and Measurement of Employability. $\mathrm{Hu}$ man Resource Management, 45, 449-476. https://doi.org/10.1002/hrm.20119

[5] Van der Heijden, B.I.J.M., De Lange, Demerouti, E. and Van der Heijde, C.M. (2009) Employability and Career Success across the Life-Span. Age Effects on the Employability-Career Success Relationship. Journal of Vocational Behavior, 74, 156-164. https://doi.org/10.1016/j.jvb.2008.12.009

[6] Djukic, M., Kovner, C., Budin, W.C. and Norman, R. (2010) Physical Work Environment: Testing an Expanded Model of Job Satisfaction in a Sample of Registered Nurses. Nursing Research, 59, 441-451. https://doi.org/10.1097/NNR.0b013e3181fb2f25

[7] Hignett, S. (1996) Work-Related Back Pain in Nurses. Journal of Advanced Nursing, 23, 1238-1246. https://doi.org/10.1046/j.1365-2648.1996.13423.x

[8] Menzel, N.N., Brooks, S.M., Bernard, T.E. and Nelson, A. (2004) The Physical Workload of Nursing Personnel: Association with Musculoskeletal Discomfort. International Journal of Nursing Studies, 41, 859-867. https://doi.org/10.1016/j.ijnurstu.2004.03.012

[9] Duffield, C., Diers, D., O’Brien-Pallas, L., Aisbett, C., Roche, M., King, M. and Aisbett, K. (2011) Nursing Staffing, Nursing Workload, the Work Environment and Patient Outcomes. Applied Nursing Research, 24, 244-255. https://doi.org/10.1016/j.apnr.2009.12.004

[10] Simon, M., Tackenberg, P., Nienhaus, A., Estryn-Béhar, M., Conway, P.M. and Hasselhorn, H.M. (2008) Back or Neck-Pain-Related Disability of Nursing Staff in Hospitals, Nursing Homes and Home Care in Seven Countries-Results from the European Next-Study. International Journal of Nursing Studies, 45, 24-34. https://doi.org/10.1016/j.ijnurstu.2006.11.003

[11] Sherehiy, B., Karwowski, W. and Marek, T. (2004) Relationship between Risk Factors and Musculoskeletal Disorders in the Nursing Profession: A Systematic Review. Occupational Ergonomics, 4, 241-279.

[12] Cheung, K., Gillen, M., Faucett, J. and Krause, N. (2006) The Prevalence of and Risk Factors for Back Pain among Home Care Nursing Personnel in Hong Kong. American Journal of Industrial Medicine, 49, 14-22. https://doi.org/10.1002/ajim.20243

[13] Beattie, J., Griffiths, D., Innes, K. and Morphet, J. (2019) Workplace Violence Perpetrated by Clients of Health Care: A Need for Safety and Trauma-Informed Care. Journal of Clinical Nursing, 28, 116-124. https://doi.org/10.1111/jocn.14683

[14] Fish, R. (2013) (Re)thinking Violence in Health Care Settings: A Critical Approach. Disability \& Society, 28, 574-576. https://doi.org/10.1080/09687599.2013.783420

[15] Bloxham, S., Barter, P., Scragg, S., Peers, C., Jane, B. and Layden, J. (2016) Person-Centered, Physical Activity for Patients with Low Back Pain: Piloting Service Delivery. Healthcare, 4, 28. https://doi.org/10.3390/healthcare4020028

[16] Breen, J. (2002) Transitions in the Concept of Chronic Pain. Advances in Nursing Science, 24, 48-59. https://doi.org/10.1097/00012272-200206000-00009

[17] McBeth, J. and Jones, K. (2007) Epidemiology of Chronic Musculoskeletal Pain. Best Practice \& Research: Clinical Rheumatology, 21, 403-425. https://doi.org/10.1016/j.berh.2007.03.003

[18] Engkvist, I.L., Kjellberg, A., Wigaeus, H.E., Hagberg, M., Menckel, E. and Ekenvall, L. (2001) Back Injuries among Nursing Personnel: Identification of Work Conditions with Cluster Analysis. Safety Science, 37, 1-18. 
https://doi.org/10.1016/S0925-7535(00)00039-4

[19] Eriksen, W., Bruusgaard, D. and Knardahl, S. (2004) Work Factors as Predictors of Intense or Disabling Low Back Pain: A Prospective Study of Nurses' Aides. Occupational and Environmental Medicine, 61, 398-404.

https://doi.org/10.1136/oem.2003.008482

[20] Estryn-Béhar, M., Duger, N. and Vinck, L. (2001) Did Working Circumstances for Women in Hospitals Change between 1984 and 1998. Revue d'Epidémiologie et de Santé Publique, 49, 397-400.

[21] Estryn-Behar, M., Kaminski, M., Peigne, E., Maillard, M.F., Pelletier, A., Berthier, C., Delaporte, M.F., Paoli, M.C. and Leroux, J.M. (1990) Strenuous Working Conditions and Musculo-Skeletal Disorders among Female Hospital Workers. International Archives of Occupational and Environmental Health, 62, 47-57.

https://doi.org/10.1007/BF00397848

[22] Pekkarinen, L., Elovainio, M., Sinervo, T., Heponiemi, T., Aalto, A.M., Noro, A. and Finne-Soveri, H. (2013) Job Demands and Musculoskeletal Symptoms among Female Geriatric Nurses: The Moderating Role of Psychosocial Resources. Journal of Occupational Health Psychology, 18, 211-219. https://doi.org/10.1037/a0031801

[23] Pattani, S., Constantinovici, N. and Williams, S. (2001) Who Retires Early from the NHS Because of Ill Health and What Does It Cost? A National Cross Sectional Study. BMJ, 322, 208-209. https://doi.org/10.1136/bmj.322.7280.208

[24] Grabbe, Y., Nolting, H.D. and Loos, S. (2005) DAK-BGW Gesundheitsreport 2005-Stationäre Krankenpflege 2005. BGW, DAK, Hamburg.

[25] Panel on Musculoskeletal Disorders and the Workplace-Commission on Behavioral and Social Sciences and Education-National Research Council (2001) Musculoskeletal Disorders and the Workplace: Low Back and Upper Extremities. National Academy Press, Washington DC.

[26] Smedley, J., Trevelyan, F., Inskip, H., Buckle, P., Cooper, C. and Coggon, D. (2003) Impact of Ergonomic Intervention on Back Pain among Nurses. Scandinavian Journal of Work, Environment \& Health, 29, 117-123.

https://doi.org/10.5271/sjweh.713

[27] IJzelenberg, W. and Burdorf, A. (2004) Impact of Musculoskeletal Co-Morbidity of Neck and Upper Extremities on Healthcare Utilisation and Sickness Absence for Low Back Pain. Occupational and Environmental Medicine, 61, 806-810.

https://doi.org/10.1136/oem.2003.011635

[28] Davis, K.G. and Heaney, C.A. (2000) The Relationship between Psychosocial Work Characteristics and Low Back Pain: Underlying Methodological Issues. Clinical Biomechanics, 15, 289-406. https://doi.org/10.1016/S0268-0033(99)00101-1

[29] Fuortes, L.J., Shi, Y., Zhang, M., Zwerling, C. and Schootman, M. (1994) Epidemiology of Back Injury in University Hospital Nurses from Review of Workers' Compensation Records and a Case-Control Survey. Journal of Occupational Medicine. Official Publication of the Industrial Medical Association, 36, 1022-1026.

[30] Lagerström, M., Wenemark, M., Hagberg, M. and Hjelm, E.W. (1996) Occupational and Individual Factors Related to Musculoskeletal Symptoms in Five Body Regions among Swedish Nursing Personnel. International Archives of Occupational and Environmental Health, 68, 27-35. https://doi.org/10.1007/BF01831630

[31] Turner, J.A., Franklin, G., Heagerty, P.J., Wu, R., Egan, K., Fulton-Kehoe, D., Gluck, J.V. and Wickizer, T.M. (2004) The Association between Pain and Disability. Pain, 112, 307-314. https://doi.org/10.1016/j.pain.2004.09.010 
[32] Van Bogaert, P., Dilles, T., Wouters, K. and Van Rompaey, B. (2014) Practice Environment, Work Characteristics and Levels of Burnout as Predictors of Nurse Reported Job Outcomes, Quality of Care and Patient Adverse Events: A Study across Residential Age Care Services. Open Journal of Nursing, 4, 343-355. https://doi.org/10.4236/ojn.2014.45040

[33] Kümmerling, A., Hasselhorn, H. and Tackenberg, P. (2003) Psychometric Properties of the Scales Used in the NEXT Study. In: Hasselhorn, H., Tackenberg, P. and Müller, B.H., Eds., Working Conditions and Intent to Leave the Profession among Nurses Staff in Europe, Report No. 7, a Research Project Initiated by SALTSA (Joint Programme for Working Life Research in Europe) and Funded by the European Commission (QLK6-CT-2001-00475).

[34] Hambleton, R.K. (1994) Guidelines for Adapting Educational and Psychological Tests: A Progress Report. European Journal of Psychological Assessment (Bulletin of the International Test Commission), 10, 229-244.

[35] Von Korff, M., Ormel, J., Keefe, F.J. and Dworkin, S.F. (1992) Grading the Severity of Chronic Pain. Pain, 50, 133-149. https://doi.org/10.1016/0304-3959(92)90154-4

[36] Kristensen, T.S. (2000) A New Tool for Assessing Psychosocial Factors at Work: The Copenhagen Psychosocial Questionnaire. National Institute of Occupational Health, Copenhagen.

[37] Kristensen, T.S., Hannerz, H., Høgh, A. and Borg, V. (2005) The Copenhagen Psychosocial Questionnaire-A Tool for the Assessment and Improvement of the Psychosocial Work Environment. Scandinavian Journal of Work and Environmental Health, 31, 438-449. https://doi.org/10.5271/sjweh.948

[38] Widerszal-Bazyl, M., Radkiewicz, P., Pokorski, J., Pokorska, J., Ogińska, H. and Pietsch, W. (2003) Who Wants to Leave Nursing in Poland? In: Hasselhorn, H., Tackenberg, P. and Mueller, B.H., Eds., Working Conditions and Intent to Leave the Profession among Nursing Staff in Europe, Report No. 7, a Research Project Initiated by SALTSA (Joint Programme for Working Life Research in Europe) and Funded by the European Commission (QLK6-CT-2001-00475), 193-202.

[39] Thacker, K., Stavarski, D.H., Brancato, V., Flay, C. and Greenawald, D. (2016) CE: Original Research: An Investigation into the Health-Promoting Lifestyle Practices of RNs. The American Journal of Nursing, 116, 24-30. https://doi.org/10.1097/01.NAJ.0000482141.42919.b7

[40] Çaylak, E. and Altuntas, S. (2017) Organizational Silence among Nurses: The Impact on Organizational Cynicism and Intention to Leave Work. Journal of Nursing Research, 25, 90-98.

[41] Krill, C., Staffileno, B.A. and Raven, C. (2012) Empowering Staff Nurses to Use Research to Change Practice for Safe Patient Handling. Nursing Outlook, 60, 157-162. https://doi.org/10.1016/j.outlook.2011.06.005

[42] Kirpal, S. (2004) Work Identities of Nurses. Between Caring and Efficiency Demands. Career Development International, 9, 274-304. https://doi.org/10.1108/13620430410535850

[43] Sochalski, J. (2002) Nursing Shortage Redux: Turning the Corner on an Enduring Problem. Health Affairs, 21, 157-164. https://doi.org/10.1377/hlthaff.21.5.157

[44] Hartvigsen, J., Christensen, K. and Frederiksen, H. (2003) Back Pain Remains a Common Symptom in Old Age. A Population-Based Study of 4486 Danish Twins Aged 70-102. European Spine Journal, 12, 528-534. https://doi.org/10.1007/s00586-003-0542-y

[45] Hignett, S. (2003) Intervention Strategies to Reduce Musculoskeletal Injuries Asso- 
ciated with Handling Patients: A Systematic Review. Occupational and Environmental Medicine, 60, E6. https://doi.org/10.1136/oem.60.9.e6

[46] Van der Heijden, B.I.J.M. (2002) Prerequisites to Guarantee Life-Long Employability. Personnel Review, 31, 44-61. https://doi.org/10.1108/00483480210412418

[47] Wilton, R.D. (2008) Workers with Disabilities and the Challenges of Emotional Labour. Disability \& Society, 23, 361-373. https://doi.org/10.1080/09687590802038878

[48] Harvey, C., Thompson, S., Pearson, M., Willis, E. and Toffoli, L. (2017) Missed Nursing Care as an "Art Form": The Contradictions of Nurses as Carers. Nursing Inquiry, 24, 1-8. https://doi.org/10.1111/nin.12180

[49] Ladegaard, Y., Skakon, J., Elrond, A.F. and Netterstrøm, B. (2017) How Do Line Managers Experience and Handle the Return to Work of Employees on Sick Leave Due to Work-Related Stress? A One-Year Follow-Up Study. Disability and Rehabilitation, 41, 44-52. https://doi.org/10.1080/09638288.2017.1370733

[50] Schaefer, J.A. and Moos, R.H. (1996) Effects of Work Stressors and Work Climate on Long-Term Care Staff's Job Morale and Functioning. Research in Nursing \& Health, 19, 63-73. https://doi.org/10.1002/(SICI)1098-240X(199602)19:1<63::AID-NUR7>3.0.CO;2-J

[51] Chen, T., Chang, P. and Yeh, C. (2004) A Study of Career Needs, Career Development Programs, Job Satisfaction and the Turnover Intentions of R\&D Personnel. Career Development International, 9, 424-437. https://doi.org/10.1108/13620430410544364 